\title{
Implementation of technology enhanced activities for teaching slope in daily life situations
}

\author{
Seçil YEMEN KARPUZCU, Kütahya Dumlupınar University, Turkey, secil.karpuzcu@dpu.edu.tr, \\ ORCID: 0000-0002-2150-000X \\ Mine IŞIKSAL BOSTAN, Middle East Technical University, Turkey, misiksal@metu.edu.tr, \\ ORCID: 0000-0001-7619-1390
}

\begin{abstract}
This study aims to present a mathematics teaching content aiming to support the teaching of slope for understanding slope conceptually in the classroom environment using computers and dynamic mathematics software. Within the scope of an implemented instructional sequence, the developed and also open to development steps of the activities integrated with GeoGebra files were evaluated so that eighth-graders can make sense of the slope concept in daily life situations. The findings revealed that the implementation of the instructional sequence prepared to explain the slope of a physical structure/object through activities integrated with GeoGebra files involving various situations on sloperelated and non-slope related attributes offers a rich environment for mathematics teaching-learning. The findings also revealed that there may be some difficulties during implementation and how these difficulties can be overcome. As a result of the study, suggestions are made for future studies to be conducted on this topic.
\end{abstract}

Keywords: Slope, dynamic mathematics software, computer assisted classroom environment, middle school mathematics curriculum

Received: 18.06 .2018

Accepted: 15.07 .2018

Published: 15.01 .2021

\section{INTRODUCTION}

The concept of slope is one of the topics that students have difficulty in many respects. First, students have difficulty in interpreting the slope of an object/feature (e.g. roof, stairs, and road) as a ratio in their daily life situations (Lobato \& Thanheiser, 2002). In other words, students have difficulty in understanding the numerical value of slope as a ratio and that slope is a ratio representing the measurement of steepness (Stump, 2001). This difficulty can be attributed to the fact that students are not aware of the quantities ${ }^{1}$ that affect and do not affect the slope of an object (Lobato \& Thanheiser, 1999, 2002; Stump, 2001). First, considering the quantities that do not affect slope, we can say that, according to the findings of Lobato and Thanheiser (2002) and our interviews with mathematics teachers, students often make a mistake by associating the slope of an object with the length of that object. Put differently, for an oblique structure/object, students have difficulty in interpreting that there are two different measurements of its length and slope. Secondly, given the quantities affecting slope, in an interview conducted by Lobato and Siebert (2002) in an instructional experiment, an eighth-grader did not give the same importance to the height of the ramp (vertical length) and the base of the ramp (horizontal length) while considering the slope of the ramp; he clearly gave more importance to the height. Moreover, in Lobato's (2002) study (cited in Lobato \& Siebert, 2002), high school students even had difficulty in establishing relationships between the measurable quantities of an object (e.g. the base and height of the ramp) that affect the slope of an object. In other words, it is not easy for students to think of the slope of an object in daily life situations by considering the relative positions of the vertical and horizontal lengths of the object. Since slope is a ratio and making sense of slope is related to proportional and quantitative thinking (Lobato \& Siebert, 2002; Lobato \& Thanheiser, 2002; Thompson, 1994), the problem is developing a learning-teaching way for conceptual

\footnotetext{
${ }^{1}$ Thompson's (1994) understanding of quantity is followed here. Here, quantity is not a number, but the property of an object with measurable properties and numerical value.
} 
understanding of slope by students as suggested by Cheng, Star, and Chapin (2013). This problem was the reason for initiating the present study. Therefore, this study is based on the idea that an instructional sequence that considers the preceding student difficulties and involves activities aiming to make sense of slope in daily life can be beneficial for learning and teaching.

It is also believed that the use of dynamic technology in teaching different subjects in mathematics contributes to how students make mathematical explanations and mathematical generalizations (Jones, 2000). In addition, the use of dynamic software in the classroom environment in teaching subjects such as functions, equations, and graphs has been shown to affect students' academic achievement and attitudes towards mathematics (Lagrange, 2010; Yemen, 2009). However, it is known that adaptation of these technologies to classroom teaching practices is not easy for teachers (Doerr, Ärlebäck \& O'Neil, 2013; Drijvers, Tacoma, Besamusca, Doorman \& Boon, 2013; Monaghan, 2004; Ruthven, Deaney \& Hennesy, 2009). For this reason, it is believed that designing, implementing and evaluating teaching experiences supported by dynamic software to make sense of a concept will contribute to the development of both learningteaching practices and theories. Such an evaluation can also guide teachers, teacher educators, and researchers by offering a trajectory for learning and teaching slope with dynamic mathematics software.

GeoGebra, which is open source dynamic software, allows users to explore a concept through various representations and views (algebra, graph, spreadsheet, etc.). Therefore, it provides a meaningful learning and teaching environment by dynamically associating visual, symbolic, graphic, and table representations to teach the concept of slope. In this study, GeoGebra software used in conjunction with computer technology stands out. GeoGebra software can be used effectively in classroom teaching in different ways from university level to elementary school mathematics (Ayvaz-Reis \& Özdemir, 2010; Hohenwarter, Hohenwarter, Kreis, \& Lavicza, 2008; Samur-Turk \& Akyuz, 2016; Tatar \& Zengin, 2016). In this study, GeoGebra files were prepared to be used within the scope of computer-assisted instruction based on GeoGebra software in order to enable students to think and discuss on slope individually and in groups. In addition to the designed GeoGebra files, activity sheets containing mathematical tasks were also designed to use in teaching. In other words, GeoGebra files integrated into math tasks within the activity sheets were developed to ensure meaningful learning for students. These activity sheets and GeoGebra files were developed for an instructional environment in which students would first use the GeoGebra and study the concept of slope mathematically. For this reason, another element of this study is the idea that integrating activities with GeoGebra files to make sense of slope in physical situations in daily life may contribute to learning and teaching.

Thus, the aim of this study is to reveal the developed steps of the activities integrated with the GeoGebra files, primarily within the context of an instructional sequence implemented in the classroom. Secondly, in order to reveal the developmental steps of these activities, the corrections that can be made depending on the implementation and the problems experienced are presented. In this context, the daily life situations determined for the context of activities in the present study includes making sense of slope in physical situations, i.e. with objects. Within the same scope, in the study, an instructional sequence designed for eighth-grade students in a real classroom environment and incorporating activities integrated with GeoGebra files were designed and implemented.

\section{The concept of slope and its place in the curriculum}

The concept of slope is basically related to the idea of proportionality in middle school mathematics. On the other hand, Lobato and Thanhaiser (2002) interpret ratio as a measurement and define the slope of an object in physical situations as a quantity which is the result of the rate of change in the vertical length relative to the horizontal length of that object. This measurement indicating steepness can also be expressed as a ratio and this measurement is considered as an indirect measurement since it is not made directly as a measurement of length or volume (Thompson, 1994). Therefore, initially, when we consider the physical conditions in daily life, the slope is related to steepness and proportion (Cheng et al., 2013; Lobato \& Thanheiser, 2002; Simon \& Blume, 1994). In other words, calculating the slope of an object or a structure can 
actually be considered as a measure of its steepness. Ultimately, the slope of an object represents how much vertical length corresponds to the horizontal length of an object.

Similar to the way Clement (1985) deals with the covariation relationship in graphs, let us examine the concept of slope in physical situations in daily life by considering the proportional relationship. When we proportionally consider the slope of an object in a physical situation in daily life, the quantities of vertical and horizontal lengths that are connected are seen first. Thus, the slope of a straight object can be interpreted by associating it with the vertical length and horizontal length of the object, or by associating the change in vertical length and the change in horizontal length in a progressive range on that object. In both associations, the slope value can be interpreted by the changes in the vertical and horizontal lengths. However, in the first association form, this mutual exchange is considered static, i.e. only the division of vertical length by horizontal length is considered, regardless of how the vertical and horizontal length of the object changes to each other. In the second association, this mutual exchange is observed continuously and interdependently (dynamically), i.e. how much the vertical length increase corresponds to the increase in horizontal length. Thus, the slope of an object can also be calculated as the amount of change in vertical length per unit change in horizontal length (Johnson, 2015).

The relationship in this slope calculation is essentially due to the fact that the vertical length increases/decreases as the horizontal length increases/decreases considering the vertical length and horizontal length values of an object simultaneously and continuously in any range. As a result of this relationship, within the context of a concrete object whose length can vary, slope increases/decreases as the vertical length increases/decreases (vertical $>0$ ) when the horizontal length is fixed (horizontal>0), and the slope increases/decreases as the horizontal length increases/decreases (horizontal $>0$ ) when the vertical length is fixed (vertical $>0$ ). In other words, as far as the object(s) whose length may change are considered, the slope is directly proportional to the vertical length when the horizontal length is fixed, and the horizontal length and slope are inversely proportional when the vertical length is fixed. As a result of the abovementioned relationship, considering the object(s) whose length does not change but whose position can change, it is seen that as the horizontal length decreases, vertical length increases as well, and hence, slope increases. Here, it is seen that objects of the same length can have different slopes and these slopes are related to vertical and horizontal lengths. In this study, the conceptualization of slope based on these two results was the basis for the formation of the activities and tasks.

On the other hand, as opposed to steepness, the slope has very broad mathematical meanings (For example, the slope of the line as the change in the $y$-value in the unit change of $x$ value in the coordinate plane, the slope of the linear function as the constant rate of change between two quantities, and the slope of a nonlinear function at a point as the instantaneous rate of change between the two quantities). However, understanding slope as a measure of steepness and establishing its relationship with proportionality can be considered a beginning to understanding slope. For example, Teusher and Reys (2010) propose distinguishing between slope and steepness as a preparation for learning the rate of change in functions. In addition, Cheng et al. (2013) suggested developing a curriculum in which the concepts of proportional reasoning, steepness, and slope are given at middle school level. Thus, it is considered important to make sense of slope as a measure of steepness before explaining the slope of the line so that the difference between the slope of a line and the steepness of a line can be explained. In other words, examining the steepness of a line requires interpreting that line physically and geometrically, and examining the slope of a line requires interpreting that line algebraically and graphically. In other words, interpreting the slope of an object as a measure of steepness may provide a basis for geometrically interpreting the slope of a line, but interpreting the slope of a line algebraically and graphically is more than that.

When the studies in the literature are examined, it is seen that the slope concept and calculation are mostly examined based on the slope of a line (Lobato, Ellis \& Muñoz, 2003; Zahner, 2015). Few studies have examined the comprehension, computation, and interpretation of the slope of a physical object (Cheng, 2015; Cheng et al., 2013; Lobato \& Siebert, 2002; Lobato \& 
Thanheiser, 2002). Lobato and Thanheiser (2002) examined student understanding of the calculation of slope using both physical and functional situations. In their study, it is emphasized that during the teaching of the concept of slope, the factors that affect slope should be determined and the elements that do not affect the slope should be kept apart. Moreover, there are few empirical studies reporting teachers' ways of teaching about slope in the middle school classroom setting (Lobato et al., 2003; Smith, Seshaiyer, Peixoto, Suh, Bagshaw, \& Collins, 2013). In addition to this, in Turkey, some studies focused on students' individual conceptions of slope in a teaching experiment context (Deniz \& Kabael, 2017a, 2017b). Different from those, how an instructional sequence about conceptualizing the slope of an object dynamically in a computer-assisted classroom environment should be structured and how it works is an emerging issue.

Before creating an instructional sequence on the concept of slope, we observed that there was no fundamental change in how this concept took place in the middle school mathematics curriculum. In other words, in the Turkish Ministry of National Education mathematics curriculum (MoNE, 2007, 2009, 2013, 2018), the subject of slope was under algebra and equations in the eighth grade. More specifically, in the MoNE curricula $(2007,2009)$, slope was introduced with the learning outcome of "explains the slope of the line with its models" (MoNE, 2009 , p. 352), while in the other MoNE curricula $(2013,2018)$, slope was introduced with the learning outcome of "explains the slope of the line with models" (MoNE, 2018, p. 77). In both curricula, the expression "model" is thought to be used to refer to straight objects, structures, or features in physical situations in daily life. Put differently, it is thought that, the slope of an object or a structure in physical situations was calculated with these models. In this case, the expression "slope of the line" in the learning outcome includes only the geometric understanding of the line and does not include the algebraic (functional) understanding of the line and the slope of the line on the coordinate system. However, this approach to the slope of the line is not included in the learning outcome or the explanation of the learning outcome in this way. The approach of the curriculum is understood from the expression "in models related to the daily life the slope is the ratio of vertical length to horizontal length" (p. 77) and taking into account that the situation "sign of slope is not emphasized" (p. 77). Furthermore, this explanation may lead to a misunderstanding that the sign of slope exists in physical situations, but it will not be explained at this grade level.

On the one hand, the above explanation in the MoNE (2018) is valuable as it has not been mentioned in other curricula published so far, and as inappropriate examples that relate the sign of the slope of a line (independent of the coordinate system) to visuals of the physical situation were given in school books. For an inappropriate example, in the eighth-grade mathematics book of the Ministry of National Education (2012), a line is drawn parallel to the visual under the image of a child sliding downhill from the left to the right of the page and an explanation stating "the slope of the line in the picture can be thought of as negative slope" (p. 190) is made by giving a negative slope value. This can lead to a misunderstanding that the slope of a downhill road, which is pictorialized from left to right, becomes negative. As a matter of fact, the sign of slope is not possible within the context of physical conditions (i.e., road), and the context in which the sign of slope is possible is linear equations and their graphs algebraically (e.g. functions) (Lobato \& Thanheiser, 2002). On the other hand, this approach also limits the modeling of slope related to daily life with physical conditions. However, in the context of a linear functional situation, for example, a line graph (linear equation) (i.e. the graph shows the toll (TL) in relation to the distance traveled $(\mathrm{km})$, the amount of fuel remaining in the tank (liters) in relation to time (hours)) can also be considered as real-life modeling of the slope. To give a more detailed example, for a situation where we assume that a pool filled with water is discharged at a constant rate, a line graph shows the change in the amount of water in the pool over time. In that line graph, the constant, negative slope indicates that the amount of water in the pool decreases at a constant rate. In other words, although real life modeling of slope includes both physical and functional situations, there are differences in the conceptualizations of slope in these contexts. As a result, taking this distinction into consideration, the activities prepared within the scope of this study focused on making sense of the slope within the context of physical situations in daily life. 


\section{METHODS}

This study is part of a design experiment in which there is implementation of an instructional sequence integrated with GeoGebra. The present study aims to reveal the developed and open-to-development steps of the mathematics activities integrated with the GeoGebra files in an instructional sequence implemented in the classroom within the scope of a computerassisted instruction based on GeoGebra software. For this purpose, a teacher's classroom implementation environment was analyzed qualitatively using video recordings and video record transcripts. The evaluation of the implementation "focuses on finding out if the program has all its parts if the parts are functional, and if the program is operating as it's supposed to be operating" (Patton, 2008, p. 308). Thus, the evaluation involves finding out what is actually happening in the program and providing suggestions on how the program can be improved. The present study, which focuses on the evaluation of an implementation, involves the implementation of integrated activities with GeoGebra files by the eighth graders of a middle school and their mathematics teacher in a real classroom environment. In this context, we evaluated the instructional sequence by focusing on how the students and the teacher experienced this practice and what difficulties they had. As a single instrumental case study (Creswell, 2007), the focus was the instructional design including the GeoGebra files and the activity sheets within the boundary of the middle school mathematics teacher's classroom environment. Thus, a descriptive review of how the instructional sequence can be developed in the mathematics teacher's classroom is presented. In fact, in case studies, an in-depth examination of the situation is conducted in order to explain in which ways a learning environment is effective and in which aspects it should be developed (Creswell, 2007).

\section{Participants and Context}

In this study, the teacher was selected through criterion sampling, which is one of the purposeful sampling methods (Patton, 2002). Her eighth-grade students accordingly became the participants also. The teacher was selected based on the criteria of using dynamic software and computer technology in the classroom, willingness for research in mathematics education, and having teaching experience. In this context, this study was conducted in a public school with a middle school mathematics teacher with eight years of teaching experience who met these criteria. This teacher graduated from the department of elementary mathematics teaching, worked in public schools, and at the same time had a master's degree in elementary mathematics education. She is also a teacher who uses instructional materials and supports her students' participation in the class.

The public school in which the teacher works is in a low-socioeconomic status district of Ankara province. In this school, the teacher had her math classroom. This classroom has a whiteboard, a computer, a projector, a material storage with various concrete objects and materials. She arranged the class seating plan considering group work in collaboration. She has been using this seating arrangement since she started teaching. The students were seated as groups, with around six students in each group.

In the study, the instructional sequence whose prototype study had been carried out was developed by applying it in two eighth grade classes of the aforementioned teacher. In the present study, the in-class implementation findings of one class which was observed to be more willing to attend the course were included. It was stated by the teacher that the primary school success of these students was very weak and ordinary family-child relations were also weak. There were 12 female and 6 male students in the eighth-grade class.

As in the usual environment of the classroom, during the current study, the students were seated in a cluster as heterogeneous groups (six students in each group) according to their level of achievement. Besides, the students participated in the lesson individually and expressed their mathematical thoughts in a discussion environment. While some responsibilities of the students in a group changed from class to class, all students in a group shared the same responsibilities like participating in producing a solution to a task, sharing and discussing solutions with each other when working individually on a task in the activity sheet, and writing the results of their 
group on their activity sheet. Other responsibilities of the students (i.e., controller, leader) in a group were changed in rotation. The teacher allows students to study and discuss within a group and between groups and encourages them to share ideas, solutions, questions, or suggestions about the mathematical activities. Student groups have laptop access for shared use. The first author made observations without interfering with the course and recorded the implementation with video and audio recorders and screen recorders for laptop computers.

\section{Procedure}

In the present study, the activities and GeoGebra files were prepared by the mathematics teacher and the authors as a design team. The GeoGebra files, which are integrated into each activity sheet, were developed to be used by the teacher and student groups in the classroom on computers. Since these activities and GeoGebra files were prepared considering that the students have not used GeoGebra before, close attention was paid not to include steps that require students to use advanced tools.

In the process of planning and preparing the activities presented in this study, the distinction between the meaning of slope in physical and algebraic (functional) situations was considered. In this context, instead of the learning outcome stating "explains the slope of the line with its models" in the curriculum, activities were prepared considering the learning outcome of "explains the slope of a physical structure/concrete object". It was revealed in the interviews with the teacher that it may be misleading to use these models as the slope of the line model since there is no sign of the slope of the structure in concrete structures (e.g. roof, stairs, and ramp). To be more specific, it has been shown that such modeling leads to an improper deduction such that if a ramp is tilted to the right, its slope has a positive value, and if it is tilted to the left, its slope becomes negative. For this reason, it is intended to develop teaching ideas such as examining the magnitude of the slope with concrete objects and analytically examining the slope of the line in the coordinate plane (magnitude and direction) and linking them. Therefore, instead of giving students the "slope of a line model" as the beginning, the approach of giving the slope of a physical structure or a concrete object as a measure of steepness was adopted. In this respect, the teaching objectives are determined as follows: The students (1) notice and describe the slope of an object in different positions, (2) describe the slope of an object, independent of the length of the object, (3) associate the vertical and horizontal lengths of an object with its slope (4) calculate the slope of an object; (5) evaluate the effect of vertical and horizontal lengths on the slope calculation of an object as a ratio. Within the scope of these teaching objectives, the following three activities were prepared to be implemented in two class hours. These activities include calculating and interpreting the slopes of various object positions using the activity sheet and the GeoGebra file together.

\section{Activity 1. The position of the boards (PoB)}

This activity is based on calculating the slope of concrete objects of equal length at different positions. It involves using boards (i.e., wooden pieces) as concrete objects and creating ramps, then associating these situations with the GeoGebra file to solve activity questions. The materials of this activity are four boards $(60 \mathrm{~cm})$, tape measure, a laptop, the GeoGebra file, and the activity sheet (Figure 1 and Figure 2). 


\section{TAHTALARIN DURUŞU}

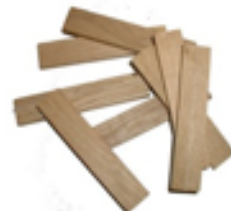

Elimizde $60 \mathrm{~cm}$ uzunluğunda tahta parçaları vardır. Bu tahta parçaları duvara yaslanmak isteniyor.

i) Buna göre bu tahtalar duvara yaslandığında duruşları her zaman aynı mıdır? Farklı duruşlarda olabilir mi?

ii) Tahtalar duvara farklı duruşlarda yaslandığında, her bir tahta için aşağıdaki tabloyu doldurunuz.

\begin{tabular}{|l|l|l|l|l|}
\hline & Tahta 1 & Tahta 2 & Tahta 3 & Tahta 4 \\
\hline Dikey uzunluk & & & & \\
\hline Yatay uzunluk & & & & \\
\hline Eğim & & & & \\
\hline
\end{tabular}

iii) Bu tahtalar içinde en fazla eğimi olan hangisidir? Sebebi nedir?

iv) Bu tahtalar içinde en az eğimi olan hangisidir? Sebebi nedir?

\section{FIGURE 1. Position of the boards activity sheet}

In the GeoGebra file of the PoB activity, the graphical view shows the board ramp, the dynamic blue line segment $(\mathrm{AB})$, the checkboxes (vertical length, horizontal length, and slope), the dashed line segments showing the horizontal and vertical lengths of the board ramp and their length values (Figure 2). The dynamic slope calculation text linked to slider-a and slope checkbox is also shown. Slider-a is a slider whose value varies between 1 and 60 and increases one by one depending on the horizontal length value of the board and is connected to the slope calculation text. Basically, the aim of this activity is to describe the slope of an object as a measurement of steepness regardless of the length of the object by examining the varying horizontal length and slope values at different positions. It is also aimed at the students to associate the vertical and horizontal lengths of the object with the slope of the object. Here, the presumed primary practice is that students explain that the quantities affecting the ramps are the vertical and horizontal lengths of the ramp without giving them the fact that the slope of an object is the ratio of the vertical length to the horizontal length at the beginning of the activity. The secondary practice is to make the measurements on the ramps with tape measures and fill the vertical and horizontal length values in the given table. The third practice is to explain that the slope of the ramp is a quantity that depends on the vertical and horizontal lengths by examining the steepness of the ramps and visualizing these situations in the GeoGebra file. In the fourth practice, students explain slope as the ratio of vertical length to horizontal length, and they further explain that "slope increases as the vertical length increases and the horizontal length decreases" or "slope decreases as the vertical length decreases and the horizontal length increases".

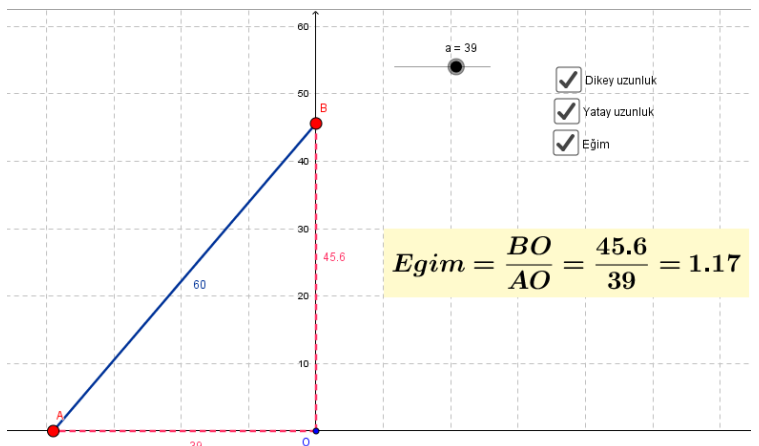

FIGURE 2. A view from the position of the boards activity GeoGebra file 


\section{Activity 2. Fire Truck (FT)}

This activity is based on calculating the slope of objects whose horizontal lengths are equal and vertical lengths vary. The materials for this activity are a laptop, the GeoGebra file, and the activity sheet (Figure 3 and Figure 4).

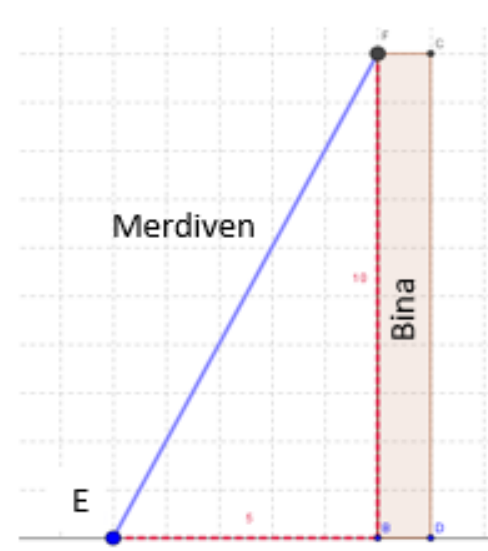

\section{İTFAIYE ARACI}

Şekildeki gibi 10 katlı bir binada yangın çıktığında, E noktasındaki itfaiye aracı merdivenini kata koyarak binadakileri kurtarmaktadır.

i) Buna göre 3. katta, 7. katta ve 9. Katta yangın olursa bu katlara konan merdivenin eğimi sırasıyla kaç olur?

ii) Yangın kaçıncı katta olursa itfaiye merdiveninin eğimi en fazla olur?

iii) Katlar yükseldikçe eğim nasıl değișiyor? Neden?

FIGURE 3. Fire truck activity sheet

The GeoGebra file of the FT activity shows the dynamic blue line segment (EF) as a fire truck ladder of varying length, the constant horizontal length in five units (EB) as the distance between the fire truck ladder and the building, red dashed line segments representing the horizontal and vertical lengths of the ladder and their length values (Figure 4). Besides, slider-f, the marked slope checkbox, and the linked dynamic slope calculation text are seen. Slider-f is a slider whose value ranges from 0 to 10 and increases one by one depending on the vertical length of the ladder and the slope calculation text. Basically, in this activity, it is aimed that students calculate the slope of an object whose horizontal length does not change in different positions but whose vertical length can change. Another aim is the students evaluate that slope increases/decreases as the vertical length increases/decreases while the horizontal length is fixed, i.e. there is a directly proportional relationship between the vertical length and slope when the horizontal length is constant.

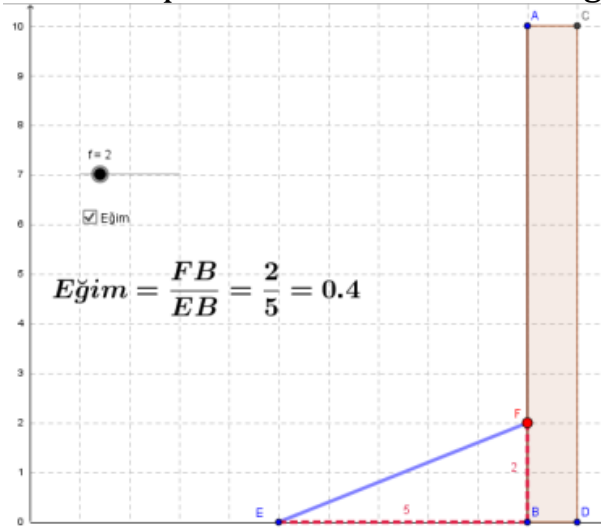

FIGURE 4. A view from the Fire Truck activity GeoGebra file

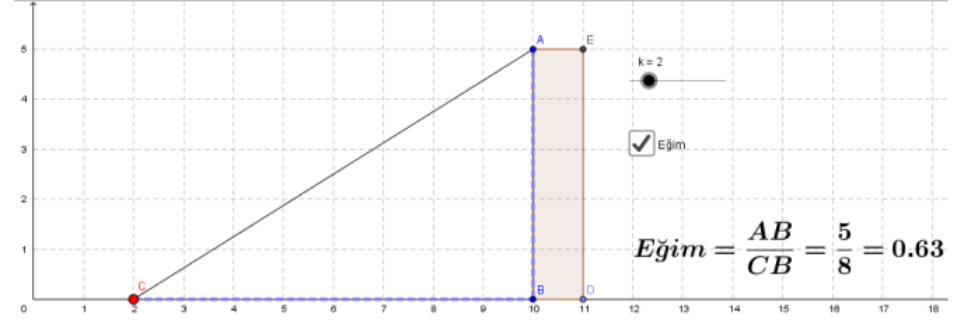

FIGURE 5. $A$ view from the Tent activity GeoGebra file

\section{Activity 3. Tent (Tt)}

This activity is based on calculating the slope of objects whose vertical lengths are equal and horizontal lengths vary. The materials for this activity are a laptop, the GeoGebra file, and the activity sheet (Figure 6). 


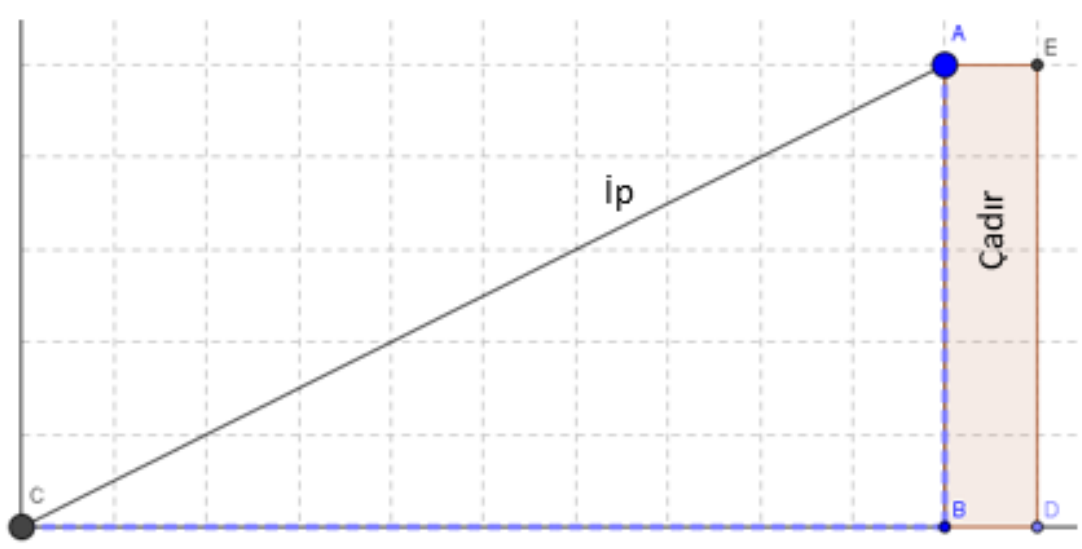

CADIR

Şekildeki gibi 5 metre yüksekliği olan bir çadır tepe sol köşesinden zemine bir ip ile en fazla C noktasına kadar bağlanabiliyor.

i) Buna göre ip çadırdan 2 metre, 4 metre ve 5 metre uzağa bağlanırsa ipin eğimi sırasıyla kaç olur?

ii) Íp zeminde hangi noktaya bağlanırsa ipin eğimi en az olur?

iii) Buna göre zemine bağlanan noktanın çadırdan uzaklaşmasıyla eğim nasıl değişiyor? Neden?

FIGURE 6. Tent activity sheet

The GeoGebra file for the $\mathrm{Tt}$ activity includes a dynamic blue line segment as a tent rope of varying length $(\mathrm{AC})$, the fixed 5-meter tent (vertical length), dashed blue line segments representing the horizontal and vertical lengths of the tent rope and their length values (Figure 5). Slider-k, a marked slope checkbox, and a slope calculation text are also seen. Slider-k is a slider whose value ranges from 0 to 10 and increases one by one and which depends on the vertical length value of the tent rope and the slope calculation text. Therefore, a change in the slider affects the rope's position, vertical length, slope calculation text, and slope value. Also, slope calculation can be controlled by the dynamic slope calculation text linked to these positions. The aim of this activity is that students calculate the slopes of an object whose vertical length does not change but whose horizontal length can change. It is also aimed that students notice slope decreases/increases as the horizontal length increases/decreases while the vertical length is fixed, i.e. there is an inversely proportional relationship between the horizontal length and the slope when the vertical length is constant.

\section{Data Analysis}

The evaluation of this implementation was made by analyzing the observation notes of the first author, student activity sheets, computer screen recordings, video recordings of the implementation and transcripts. The notes and video recordings of the researcher (the first author) were examined through analyzing instruction sessions with the teacher since she was a member of the design team. While facilitating these sessions, the researcher used the Interpersonal process recall interview method using the video-recordings of classroom teaching. In this process, the teacher watched the episodes of the video recording of the lesson, make reflections on her students' activities and her classroom teaching experience while the researcher was posing questions. To give examples, the researcher asked how students understood the slope in using concrete objects, what mathematical tools were used for a classroom mathematical practice (e.g., interpreting vertical attribute on the slope of an object).

While interpreting student activity, the interpretations were guided through the notion of classroom mathematical practices in the interpretive framework (Cobb \& Yackel, 1996). At this point, the understanding of slope in the studies of Moore-Russo, Conner, and Rugg, (2011), Lobato and Thanheiser (2002), and Stump (2001) provided guidance. For example, Lobato and Thanheiser (2002) discussed the slope of an object and the slope of a line separately. Thus, while 
Lobato and Thanheiser (2002) considered slope as a measure of steepness within the context of objects or structures in physical situations, they conceptualized the slope of an object as the rate of change in vertical distance relative to the horizontal distance. In this sense, when calculating the slope of an object, the ratio of the vertical distance to the horizontal distance at any range on the object is calculated.

In the first stage of the analysis, the students' behaviors and the teachers' behaviors were coded by the authors through open coding. In this regard, coding was performed considering the behaviors related to mathematical actions observed in the environment and expected to be observed but not observed. In addition, students' behaviors related to gestures and metaphors while using concrete objects and GeoGebra files were also considered. In the meantime, open codes related to mathematical practices of the students with explanations were shared with the teacher after the whole research process was completed. She also agreed with the related explanations about the codes. The second stage of the analysis was carried out using the continuous comparative analysis method in line with the criteria determined through the codes (Glaser \& Strauss, 2006). In this process, data of two eighth-grade classes were used and the data of the prototype study reviewed. A section from the data analysis for the PoB activity was given in Table 1 below. Based on the analysis, the findings on the implementation of the activities, students' differences and difficulties experienced in the implementation were presented in a narrative way as if a teacher was in practice in the classroom.

Table 1. A section from the data analysis

\begin{tabular}{|c|c|c|c|}
\hline $\begin{array}{l}\text { Mathematical } \\
\text { Ideas }\end{array}$ & Tools/ Images & Mathematical Practices & Gestures/ Metaphors \\
\hline $\begin{array}{l}\text { Determining } \\
\text { the influential } \\
\text { quantities on } \\
\text { the steepness }\end{array}$ & $\begin{array}{l}\text { Positioning } \\
\text { boards }\end{array}$ & $\begin{array}{l}\text { Attending the quantities } \\
\text { affecting the ramps as boards } \\
\text { (i.e. vertical and horizontal } \\
\text { lengths of the ramp) } \\
\text { Measuring the influential } \\
\text { quantities on the ramps and fill } \\
\text { the vertical and horizontal } \\
\text { length values in the given table }\end{array}$ & $\begin{array}{l}\text { Leaning the boards against the } \\
\text { wall in different positions } \\
\text { Take vertical and horizontal } \\
\text { measurements on the boards } \\
\text { using tape measures } \\
\text { Difficulties on precise } \\
\text { measurements with tape } \\
\text { measures }\end{array}$ \\
\hline $\begin{array}{l}\text { Interpreting } \\
\text { the influential } \\
\text { quantities on } \\
\text { the slope }\end{array}$ & $\begin{array}{l}\text { Dynamic } \\
\text { pictorial } \\
\text { positioning on } \\
\text { the GeoGebra file }\end{array}$ & $\begin{array}{l}\text { Associating the influential } \\
\text { quantities for the steepness of } \\
\text { the board with the slope of the } \\
\text { board }\end{array}$ & $\begin{array}{l}\text { Keeping hands upright like the } \\
\text { vertical line segment on the } \\
\text { GeoGebra file }\end{array}$ \\
\hline
\end{tabular}

The interpretations made considering the codes were shared with a second coder who is a doctoral student with experience in mathematics teaching, thus confirming the reliability of the findings. The coders had a full agreement. To ensure validity, the findings were supported by the students' activity sheets. Furthermore, the codes giving the findings worked in a different classroom environment in which the implementation was performed and in observation notes. Thus, the validity of the study was ensured by examining the other source, i.e., the changing experiences in different classroom environments.

\section{RESULTS}

The findings of this study are based on observation notes, student activity sheets, students' computer screen recording analysis, along with the video transcript analysis of the implementation. In this context, the findings were presented under the title of three activities (position of the boards, fire truck, and tent) considering (1) the implementation of the activity and (2) student differences and difficulties experienced in implementation.

\section{Activity 1. Position of the boards}

(1) At the beginning of the implementation in the classroom, it was emphasized that this activity would be done as a group and each group should use a board and a tape measure. After 
the students received the boards, each student group leaned the boards of equal length $(60 \mathrm{~cm})$ on the wall like a ramp in different positions. In this implementation, a student with learning difficulties used the board with the help of the teacher. Then, the students compared the position of the boards and discussed which one would be more comfortable/difficult to walk (Figure 7). They discussed the question of whether the position of the boards is always the same when they are leaned against the wall. In the meantime, the students reached conclusions such as these boards "have different positions", "have different angles", and "form different angles with the ground". After the teacher's question about which aspect (quantity) of the board these positions and angles change, the term "slope" was first used by the students. As the students used the term "slope", the teacher asked about the difficulty of walking on the roads/ramps if we think of them as a road/ramp, and the students stated that the slope of the ramp they chose was less steep. In the meantime, students looked at the boards of all groups, and they had in-group and classroom discussions about which slope was less/more. Thus, without any mention of the slope by the teacher, the students themselves reached the concept of slope intuitively by putting their ideas forward. With these discussions, the students associated the reasons for the different positions with the slope of the board and the angle of the board with the ground.

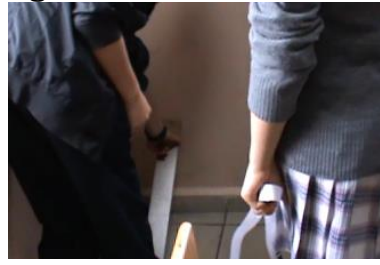

FIGURE 7. A view showing a student group leaning the board against the wall

During the implementation of the activity, the students discussed the factors affecting the slope of the boards. During these discussions, the students used expressions such as "height", "the part that goes down to the floor vertically" and "base". Besides, the students discussed whether the length of the boards affected slope. Then, the teacher opened the GeoGebra file. In the dynamic view, the teacher showed the vertical and horizontal lengths of the board by moving the slider (slider-a in Figure 2), which depends on the horizontal length and which indirectly affects the vertical length. Thus, the students examined many boards in different positions with a single slider movement. Also, without giving the numerical values, they were encouraged to use the vertical and horizontal length quantities. The students used expressions such as "OA length affects slope" and "Height [affects slope]". Thus, it was seen that the students needed to determine the vertical and horizontal lengths of the boards and find their values to determine the slopes of the boards. Some students still wanted to be confirmed:

$S$ (student): Teacher, in this [GeoGebra file] we will measure the vertical height (putting his hand vertically), won't we?

T (teacher): We also said there is somewhere else (another quantity).

S: Downward.

T: Horizontal (horizontal length).

The teacher confirmed the students. Although the students did not ask, she asked about the other quantity affecting slope. After these discussions, the students answered the first question (i.e., "When these four boards lean against the wall, are the positions of boards always the same? Can they be in different positions?) in the activity sheet (Figure 8).

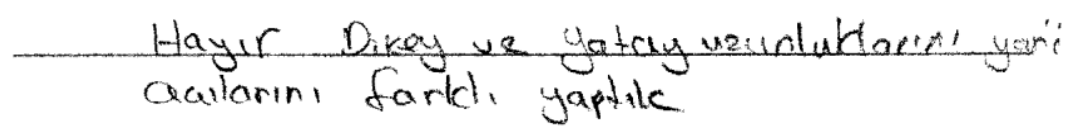

FIGURE 8. Student response to the first question in the position of the boards activity

As shown in Figure 8, a student wrote: No. We made the vertical and horizontal lengths different, so we made the angles different. Besides, students also mentioned the relation between the angle and the position of the boards. While confirming that slope and the angle between the 
board and the ground are interrelated, the teacher did not give information about the relation between the slope and the measure of angle. Thus, it is seen from students' behavior and written responses that they realized that without making a slope calculation, an object will have different slopes in different positions and that these slopes are independent of the length of the object but depend on their vertical and horizontal lengths. It was observed that the students compared the visual situation in the GeoGebra file with the situation they created with the concrete object and examined what the vertical and horizontal lengths corresponded to. For example, a student made an explanation to his group members "(By referring vertical line segment on GeoGebra) this part is vertical length on the board" while moving his finger from the part of the board touching the wall to the ground, as if he were drawing a vertical line segment.

Then, in the second question, the students measured the vertical and horizontal lengths of their boards in meters and filled in the vertical and horizontal length cells in the table. However, they did not measure slope because they still did not know slope calculation text in GeoGebra. All student groups shared the values of the boards with each other. At this point, the teacher re-used the GeoGebra file. After the teacher ticked the vertical and horizontal length checkboxes (the vertical segments and horizontal length segments and values are visible) in GeoGebra, she moved the slider (slider-a) and many board positions were seen on the board. Then, the students discussed how the vertical and horizontal lengths affect the slope of the board. The students visually noticed that the slope of the boards of equal length increased as the vertical length value increased and the horizontal length value decreased. For example, they used statements such as "Height increases the slope" and "as horizontality decreases, the slope increases". Also, while examining many board positions with sliders (sliders-a) in the GeoGebra file, the students discussed how the slope of an object can be calculated with the vertical and horizontal length values of that object without seeing slope calculation text in GeoGebra. Some successful students in the class associated slope with the ratio of these two lengths:

T: How can we establish the relationship between slope and these two lengths, vertical length and horizontal length? What kind of a relationship can it be? What can be the operation?

S1: Division.

S2: The ratio of vertical to horizontal.

On the other hand, many students in the classroom could not express this proportional relationship at first. While the teacher did not provide an explanation or formula for calculating the slope of a concrete object, she then explained that the slope of an object would then be calculated as the ratio of the vertical length of that object to its horizontal length. Thus, the students calculated the slope of the boards as the ratio of the vertical length to the horizontal length using the vertical and horizontal length values they found. At this point, it was observed that the students expressed slope as the ratio of vertical length to horizontal length and visually began to associate the increase in slope with vertical length increase and horizontal length decrease.

Then, the students began to link the concrete objects in their hands and the dynamic visual and symbolic expressions in GeoGebra. In the meantime, the teacher moved the dynamic view with the horizontal length slider (slider-a) after checking the vertical length, horizontal length, and slope checkboxes in the GeoGebra file (Figure 2). The students compared slope calculations and vertical and horizontal lengths for four different boards using the table in the activity sheets and the GeoGebra file. Furthermore, the students observed the vertical and horizontal lengths of the other boards in different positions from these boards and the slope calculation made with these lengths in the slope calculation text based on the dynamic view. The students again discussed how slope changes when the quantities (vertical length and horizontal length) of the board change. Thus, the students began to make sense of the relationship between vertical length, horizontal length, and slope values in many different positions.

Afterwards, the students checked the vertical length and slope values in their activity sheets by adjusting the horizontal lengths of the board ramps they created with the slider on the dynamic view created in the GeoGebra file. In other words, the horizontal length value measured by the students was adjusted with the slider and the students checked the corresponding vertical length 
value and the slope value. In the meantime, students' operation errors were corrected. The students observed that a decimal value could be obtained as a result of the division operation in slope calculation.

As the last step of the activity, the teacher activated the "trace" feature of the line segment (i.e. board) in the GeoGebra file and the vertical length, horizontal length, and slope checkboxes (Figure 9). Thus, the dynamic visuals and values of the board, vertical and horizontal lengths, and the dynamic slope calculation text were seen simultaneously. A screenshot of a moment is given in Figure 9.

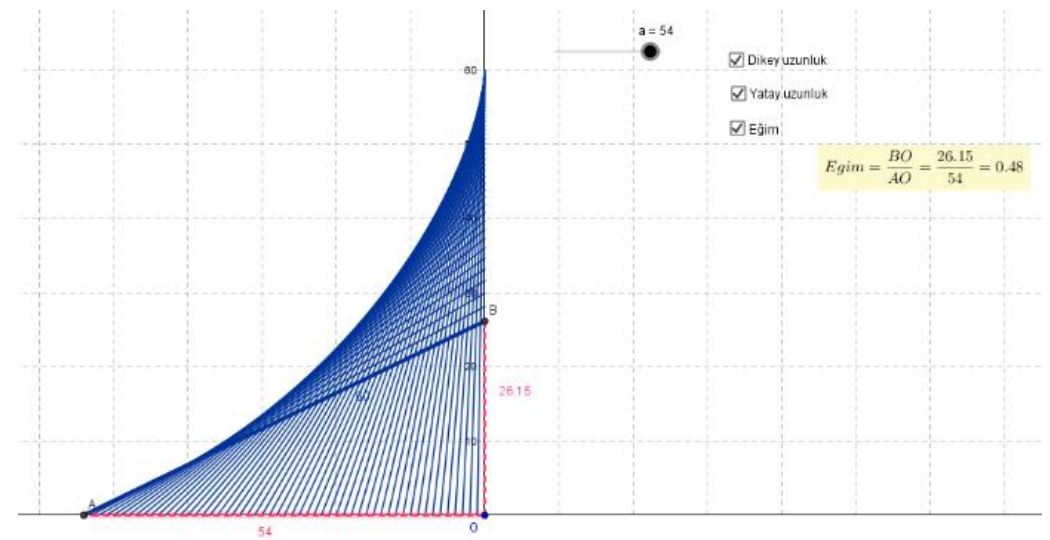

FIGURE 9. Another view from the position of the boards GeoGebra file

Then, the slider was moved and the students evaluated all the positions of the board and all the slope calculations dynamically and in relation to each other. They discussed and answered the last two questions on the activity sheet in which the slope of the boards was the least and the steepest (Figure 10).

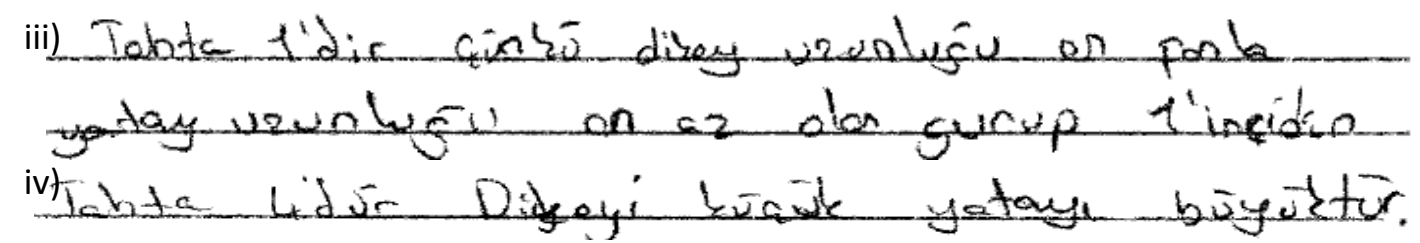

FIGURE 10. Student response to the third and fourth questions in the position of the boards activity Here, the students evaluated the effect of the vertical and horizontal length values of an object on slope calculation. For example, when calculating the slope values of the fixed-length board in different positions, the students made evaluations such as "Horizontal length decreases as vertical length grows" and "Vertical length is the most in ours, and horizontal length is the least in ours as well". It was seen that the students made comments among themselves as "Ours has the smallest slope because verticality is little and horizontality is much" and "The first board has the largest slope and the fourth board has the smallest, don't they? Slope is the vertical divided by horizontal." Thus, the students defined slope as the steepness measurement of an object and described the slope of the object by associating the vertical and horizontal lengths regardless of the length of the object. The description turned into "The ratio of vertical length to horizontal length is slope".

(2) In this activity, the following findings came to the fore when examining student differences and the difficulties experienced in practice. One of these is that the students could not make precise measurements when the concrete objects were leaned against the wall. Although the teacher told them to pay attention to this, it was seen that there were errors in student measurements. The other one was that the students had difficulties in dividing operation with decimals. However, these errors and difficulties were corrected in the GeoGebra graph view. Besides, the teacher acted slowly in the transition from one GeoGebra tool to another, which led to a slowdown in the teacher's own pace, but no problems were observed as far as students' understanding was concerned. 


\section{Activity 2: Fire Truck}

(1) At the beginning of the implementation, it was explained that this activity would be done as a group and that each group can use the GeoGebra file. The teacher handed out the activity sheet and the students discussed how the fire ladder would stand on different floors where there is fire. The students and the teacher read the activity and talked about how a fire ladder would approach the building in case of fire:

T: What is the problem situation?

$S$ : If there is a fire in a ten-storey building-

T: But it does not have to be on the tenth floor. On what floor can it be?

$S$ : It says on the third and seventh floor on the activity sheet.

After the students understood the given context, the teacher explained to the students that the point that changes by moving the slider on the GeoGebra screen shows the floor where there is fire. The teacher explained the tools in the GeoGebra file to the student groups. In the meantime, the students examined how the ladder stood by moving the slider in the GeoGebra file. Thus, it was seen that the students established the relationship between the slider, the dynamic view, and the context of the activity to perform the activity. In addition, the students discussed in which situation it was easier / harder to climb the ladder.

During the implementation of the activity, the students first examined the stairs in the event of a fire on the third, seventh, and ninth floors. They created these fire ladder situations on the GeoGebra graphics view and calculated their slopes. For example, the students made verbal explanations such as "we divided three into five" and "we found the ratio of the vertical to the horizontal". After the students made the slope calculation with paper and pencil, they ticked the slope checkbox with the help of the teacher and checked their answers. Many students wrote the slope calculation as a ratio in these three cases, but some had difficulty writing in decimal. The students who made an operation mistake corrected those with GeoGebra, and the students who could not express slope in decimal checked the decimal expression of the slope with the GeoGebra file. In the meantime, the teacher visited the student groups one by one and asked between which values they found the ratio. The students discussed why they calculated the ratio in that way. For example, the students found that when there was a fire on the third floor, there were 3 units of vertical length and 5 units of horizontal length, and 3 units of vertical corresponded to 5 units of horizontal. It was concluded that the students understood the slope as a geometric ratio, i.e., they interpreted slope as the ratio of the vertical length to the horizontal length.

In the next step of the activity, the students identified the position with the greatest slope among the ladder positions and discussed the reasons behind. The students both discussed the slope of the ladder in the situations they calculated (third, seventh and ninth floor) and also considered the position of the ladder with the greatest slope (ii, Figure 11): It would be 2 on the 10 th floor because vertical length is the maximum. In the meantime, the students created and examined all the positions using the GeoGebra file. It was concluded that the students understood that slope is a physical feature of the ladder (quantity) and that the position of the ladder is related to this quantity.

ii)

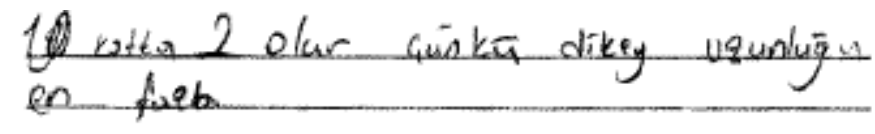

iii)

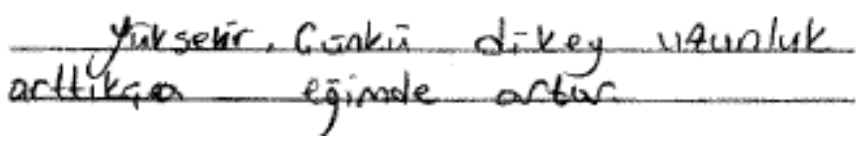

FIGURE 11. Student response to the second and third questions in the fire truck activity

As the final step of the activity, the teacher asked which quantity (which value) was fixed in the fire truck ladder situation. Thus, using the dynamic view in the GeoGebra file, the students evaluated how the change in vertical length changes the slope while the horizontal length is 
constant in this situation. The students then answered the question of how the slope of the ladder changes as they go up the floors (iii, Figure 11): "Slope increases because as vertical length increases, slope also increases."

At the end, using the GeoGebra file (i.e, ticking the vertical length and slope checkboxes, the dynamic slope calculation text and dynamic ladder changed depending on the slider), the teacher emphasized how the vertical length affects the slope when the horizontal length is constant, and she said that a comment can be made on the proportional relationship between the vertical length and slope:

T: So, what happened to the slope gradually? You said it increased. Why? What happened when the horizontal was constant?

$S$ : Vertical length increased.

As student group discussions revealed, the students also took into account the quantity of horizontal length when interpreting the relationship between slope and vertical length. Therefore, the students reached the conclusion that in a physical situation, it is not always correct to say that slope is high when verticality is high because the horizontal length should also be taken into consideration.

Although not included in the activity sheet, the teacher asked which floor was the most comfortable for the firefighters while they were climbing up the fire ladder and moved the slider so that the vertical length value of the ladder was zero (0). In this case, the students discussed slope calculation and therefore the division of zero by a number (e.g. $\frac{0}{5}$ ). Furthermore, the students examined this position (horizontal position) of the ladder on the GeoGebra graphics view and found out that the zero-value displayed as a result of slope calculation is the slope value.

(2) There was no moment when students had difficulty. The students used the GeoGebra file and the activity sheet together and made the expected comments. Even when slope was zero, they visually depicted the situation on the GeoGebra file, calculated slope symbolically, and verbally expressed that slope was zero. Although there was no activity question related to this during lesson planning, it was decided during the evaluation of the teaching that this problem could be included in the activity sheet (For example, when climbing the fire ladder, which floor has the least steepness? Why? What is the slope of the ladder on this floor?)

\section{Activity 3. Tent}

(1) At the beginning of the implementation, it was explained that each group could use GeoGebra file on their computers. The teacher handed out the activity sheet and the students read the activity. Then, the students discussed how the rope of this tent would be positioned. Using statements like "Putting it away. It is related to horizontality", the students tried to make sense of the situation. In addition, by saying "Height remains fixed", and "The place where we sink the rope is changing", they revealed the changing and fixed quantities in the situation. The students opened the GeoGebra file and examined the position of the tent rope moving the slider. They discussed in which situations the rope was steeper/more sloping. The teacher nevertheless explained the use of GeoGebra to the student groups.

During the implementation, the students calculated the slopes when the rope was tied 2 meters, 4 meters and 5 meters away from the tent (Figure 12). They checked their answers using the GeoGebra file. The teacher asked between which values they found the ratio, and the students discussed why they set the ratio in that way. For example, when the students tied the rope 2 meters away from the tent, they determined that there were 5 meters of vertical length and 2 meters of horizontal length, and they found that 2 meters of horizontality corresponds to 5 meters of verticality.

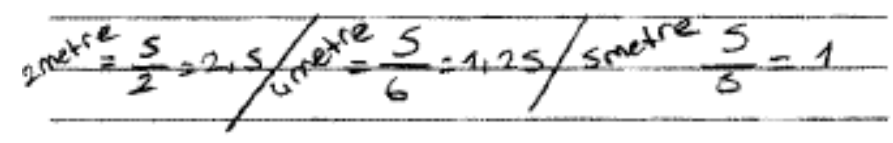

FIGURE 12. Student response to the first question in the tent activity 
In the next step of the activity, the students discussed the positions with the least slope and the meaning of it. They stated that the steepness of the rope decreases when slope decreases. Then, they answered the question of "Considering the given situations, at which point the rope is attached to the ground, does the slope of the rope become the least?". The students created and studied all the positions using the GeoGebra file.

In the final step of the activity, the teacher asked which value (which quantity) was fixed as far as the tent rope is concerned. Using the GeoGebra file, the students evaluated how slope changes if the horizontal length changes while the vertical length is constant. Then, the students answered the question of how the slope of the rope changes as the point to which the rope is tied gets away from the tent. At the end of the activity, using the GeoGebra file (i.e., horizontal length and slope checkboxes were ticked, and the dynamic slope calculation text and the dynamic rope changed depending on the slider), the teacher emphasized that comments can be made on how the change in horizontal length affects slope while the vertical length is constant and on the proportional relationship between horizontal length and slope. Thus, the students concluded that, in a physical situation, it is not always correct to say that the slope is less if horizontality is more as vertical length should also be taken into consideration. As a result, the students calculated the slope as a ratio.

Although not included in the activity sheet, the teacher moved the slider so that the horizontal length value of the rope was zero (0). In this case, the students discussed the steepness of the rope, slope calculation, and thus the division of a number by zero (e.g. $\frac{5}{0}$ ). The students said "zero" without seeing the GeoGebra symbol. After seeing the " $\infty$ "'symbol on the GeoGebra screen, they said "infinite". Some students stated that the slope is undefined because of the division process. In addition, the teacher stated that the symbol " $\infty$ ", which appears on the GeoGebra screen as a result of slope calculation, is an infinite symbol and that infinity does not have a number value. Finally, based on the teacher's explanations, the students stated that in this case (in the vertical position), and the result of the division process and the slope value were undefined, and slope was incomputable.

(2) As far as difficulties are concerned, it was observed that in practice, the students had difficulty in connecting horizontal distance with the number value at that point where the rope was located in the GeoGebra file. Although the file given to the students was prepared with the idea that the horizontal number values would help the students determine the horizontal length value like a ruler, it was concluded that counting the horizontal units on the grid consisting of unit squares would be more understandable for the students. Besides, while the slope was undefined, it was observed that the students found the image in GeoGebra understandable, but it was not appropriate to display the slope value with the infinite symbol. Thus, it was decided to enter this slope object in the slope calculation text after entering the slope value as an object (numeric value appears as undefined in algebra view, while it appears as "?" in the graphics view) using the slope tool in GeoGebra when the slope of a steep object is undefined. With this change in the GeoGebra file, the slope text would look like 'slope $=\frac{A B}{C B}=\frac{5}{0}=$ ?'. Although there was no activity regarding the undefined slope during lesson planning, it was decided that such a problem may be included in the activity sheet during the evaluation phase of the teaching, considering the implementation (For example, at which point should the rope be tied to the ground so that the rope is upright? Explain your reasoning? Calculate the slope in this case.).

\section{DISCUSSION and CONCLUSIONS}

During the implementation and evaluation stages of the activities, it was concluded that the students "explain the slope of a physical structure/concrete object", and thus, the teaching objectives determined in line with this learning outcome were found to be applicable. It was also seen that the activities and files ${ }^{1}$ prepared to achieve these teaching objectives could improve students' understanding of slope as a ratio. In addition, it was concluded that this course can be

\footnotetext{
${ }^{1}$ All the GeoGebra files can be accessed at https://www.geogebra.org/m/HxgXhgPA as a GeoGebra book.
} 
applied in real classroom environments with some changes and improvements in activity steps and GeoGebra files.

While preparing the activities in this study, the basic idea was to dynamically give an understanding of the slope of an object as the ratio of the vertical length of the object to the horizontal length, considering the quantities associated with the slope. Thus, students' processes of calculating the slope of objects through concrete objects and GeoGebra files were considered. In this context, it was concluded that in the first stage, detecting vertical and horizontal components on the object (both the dynamic visual in GeoGebra and the concrete object) is beneficial in understanding slope calculation as it enables to see the effects of these components on slope as direct visualization and symbolically with numerical values. In other words, it is thought that examining the proportionality of the vertical length, horizontal length, and slope values, which vary continuously and depending on each other over a fixed length object for the understanding of slope calculation on a dynamic view, can support the learning process. Thus, the students developed the idea that objects of equal length may have different slopes, established the relationship that slope of an object depends on the vertical length and horizontal length, and described the slope as a ratio. On the other hand, as Cheng (2015) points out, it is thought that in addition to having strong proportional thinking skills to develop this thinking, students should be able to relate proportionality and slope while calculating it as a measure of steepness and to establish a dual relationship of the quantities of steepness. In the present study, it was seen that the students showed this proportional way of thinking about slope better in their interpretations at the end of the three activities.

In addition, it was seen that the students examined the directly proportional relationship between slope and vertical length when the horizontal length was fixed and the inverse proportional relationship between slope and horizontal length when the vertical length was fixed, which kept the students away from the misconceptions such as slope-height confusion. Furthermore, students' understanding that the slope of an object changes as a result of the relationship of these two quantities with each other improves the understanding that slope corresponds to the ratio of these two quantities. Therefore, when evaluating the quantities that affect slope, examining the relationship between slope and one quantity while the other quantity is fixed by using the GeoGebra file can strengthen the understanding that slope is a ratio, both as a dynamic visual and a symbolic representation. Finally, as Cheng et al. (2013) suggested, it is thought that an instructional environment is created that relates proportionality with the understanding that slope is a ratio showing the measure of steepness.

Moreover, when the way activity sheets were used by the students was evaluated, it was decided to make some revisions on the sheets for subsequent implementations. While carrying out the Fire Truck and Tent activities, it was observed that some students also needed written explanations about the situations which were depicted as examples in the activity sheet, especially when they were working individually. Therefore, in the Fire Truck activity, it was considered appropriate to indicate in writing that "A ladder that reaches the 10th floor as shown here is seen" and in the Tent activity, it was considered appropriate to indicate that "It is seen in the picture that the tent rope is tied 10 meters away from the tent".

Two important slope concepts associated with the last two activities during the implementation are zero slope and undefined slope. Initially, the fire truck (fixed horizontal, changing vertical) and tent (fixed vertical, changing horizontal) activity sheets do not include steps for these concepts, but as a result of the implementation and evaluations during the course, it was seen that in physical conditions, the students could dynamically interpret the conditions when the slope was zero or undefined with both visual and symbolic representations. Thus, it is considered appropriate that students interpret the situations where the slope is zero and undefined on the objects and the related tasks are on the activity sheet. As a result, if middle school students are expected to acquire physical property, the real-life situations, and geometric ratio as conceptions of slope apart from the slope of line graphs (Moore-Russo et al., 2011), it is thought that including the aforementioned learning outcome in the middle school mathematics curriculum may be useful to teachers, book writers, and students. Thus, it is thought that students can improve awareness of the slope of an object. 
In the meantime, the findings of this study should be considered in light of some limitations. In this study, the teacher was an experienced teacher using dynamic mathematics software. Therefore, this study is limited to those teachers and their students. Considering this situation, the characteristics of the participant teacher and her students and the classroom environment were described to allow for comparisons with other samples and contexts in future research. Meanwhile, a prototype study had been carried out with another teacher with similar characteristics in another public school before this main study was carried out. Besides, data episodes in a class implementation were tested for other episodes in the same class and another class of the participant teacher during the data analysis. Also, those data were tested by data triangulation with teacher interviews, students' materials, and field notes. The second limitation is about the researcher's role and bias in qualitative research which was handled by collecting audio and video data before, during, and after the implementation and coding data with a second coder. At last, data of the research that this study belongs to was limited to the teaching of linear equations for eighth-grade students who had experience in proportional reasoning in the previous grade. Therefore, that may make a difference in students' learning process in the study. In this context, future studies may investigate how understanding the steepness of a line as the geometric and physical understanding of the line can help students grasp that the sign of the slope of a line indicates a decreasing, increasing, horizontal behavior of a line graph (or a linear functional situation). Moreover, how this understanding can contribute to the understanding of the slope of the line as the constant rate of change in the sense of linear functions can be investigated.

\section{REFERENCES}

Ayvaz-Resiz, Z., Özdemir, S. (2010). Using GeoGebra as in information technology tool: parabola teaching. Procedia Social and Behavioral Sciences, 9, 565-572.

Cheng, D. (2015). Roofs, stairs and lines: middle school students' strategies in solving steepness problems. The Online Journal of New Horizons in Education, 5(1), 87-102.

Cheng, D., Star, J. R., \& Chapin, S. (2013). Middle school students' steepness and proportional reasoning. New Waves-Educational Research \& Development, 16(1), 22-45.

Clement, J. (1985, July). Misconceptions in graphing. In Proceedings of the Ninth International Conference for the Psychology of Mathematics Education (Vol. 1), pp. 369-375. Utrecht, The Netherlands: Utrecht University.

Cobb, P., \& Yackel, E. (1996). Constructivist, emergent, and sociocultural perspectives in the context of developmental research. Educational Psychologist, 31(3-4), 175-190.

Creswell, J. W. (2007). Qualitative inquiry and research design: Choosing among five approaches (2nd ed.). Thousand Oaks, CA: Sage.

Deniz, Ö., \& Kabael, T. (2017a). 8. sınıf öğrencilerinin eğim kavramını oluşturma süreçleri. Eğitim ve Bilim, 42(192), 139-172.

Deniz, Ö., \& Uygur-Kabael, T. (2017b). Students' mathematization process of the concept of slope within the realistic mathematics education. Hacettepe University Journal of Education, 32(1), 123-142.

Doerr, H. M., Ärlebäck, J.B., \& O’Neil, A. H. (2011). Teaching practices and modelling changing phenomena. In B. Ubuz, C. Haser, \& M. A. Mariotti (Eds.), Proceedings of the Eighth Congress of the European Society for Research in Mathematics Education (CERME 8, February 6 - 10, 2013 (pp. 1041-1050). Ankara, Turkey: Middle East Technical University and ERME.

Drijvers, P., Tacoma, S., Besamusca, A., Doorman, M., \& Boon, P. (2013). Digital resources inviting changes in midadopting teachers' practices and orchestrations. ZDM - International Journal on Mathematics Education, 45(7), 987-1001.

Glaser, B. G., \& Strauss, A. L. (2006). The discovery of grounded theory: Strategies for qualitative research. New Brunswick: Transaction Publishers. (Original work published in 1967).

Hohenwarter, M., Hohenwarter, J., Kreis, Y., \& Lavicza, Z. (2008). Teaching and calculus with free dynamic mathematics software GeoGebra. ICME 11 Mexico 2008. 11th International Congress on Mathematical Education.

Johnson, H. L. (2015). Together yet separate: Students' associating amounts of change in quantities involved in rate of change. Educational Studies in Mathematics, 89(1), 89-110.

Jones, K. (2000). Providing a foundation for deductive reasoning: students' interpretations when using dynamic geometry software and their evolving mathematical explanations. Educational Studies in Mathematics, $44(1 / 2), 55-85$. 
Lagrange, J. B. (2010). Teaching and learning about functions at upper secondary level: designing and experimenting the software environment Casyopée. International Journal of Mathematical Education in Science and Technology, 41(2), 243-255, DOI: 10.1080/00207390903372395

Lobato, J., \& Siebert, D. (2002). Quantitative reasoning in a reconceived view of transfer. The Journal of Mathematical Behavior, 21(1), 87-116.

Lobato, J., \& Thanheiser, E. (1999). Re-thinking slope from quantitative and phenomenological perspectives. In F. Hitt \& M. Santos (Eds.), Proceedings of the 21st Annual Meeting of the North American Chapter of the International Group for the Psychology of Mathematics Education (Vol. 1, pp. 291-297). Columbus: OH: ERIC. https://doi.org/ERIC Document Reproduction Service No. ED 433998

Lobato, J., \& Thanheiser, E. (2002). Developing understanding of ratio as measure as a foundation for slope. In B. Litwiller (Ed.), Making sense of fractions, ratios, and proportions: 2002 Yearbook (pp. 162-175). Reston, VA: National Council of Teachers of Mathematics. Retrieved from http://www.hoodriver.k12.or.us/cms/lib06/OR01000849/Centricity/Domain/860/Developing Ratio-as-Measure as a Foundation for Slope.pdf

Lobato, J., Ellis, A. B., \& Muñoz, R. (2003). How "focusing phenomena" in the instructional environment support individual students' generalizations. Mathematical Thinking and Learning, 5(1), 1-36.

Ministry of National Education [MoNE] (2007). İlköğretim matematik dersi 6-8. sinıflar öğretim programı ve kılavuzu (Middle school mathematics curriculum for grades 6, 7, and 8). Ankara: MEB.

Ministry of National Education [MoNE] (2009). İlköğretim matematik dersi 6-8. sinıflar öğretim programı ve kılavuzu (Middle school mathematics curriculum for grades 6, 7, and 8). Ankara: MEB.

Ministry of National Education [MoNE] (2012). Ilköğretim matematik 8 ders kitabı (5. Baskı) (Middle school grade 8 Course book). Ankara: MEB.

Ministry of National Education [MoNE] (2013). Ortaokul matematik dersi (5, 6, 7 ve 8. sinıflar) öğretim program (Middle school mathematics curriculum for grades 5, 6, 7, and 8). Ankara: MEB.

Ministry of National Education [MoNE] (2018). Matematik dersi öğretim programı (ilkokul ve ortaokul 1, 2, 3, 4, 5, 6, 7, ve 8. siniflar) (Mathematics curriculum for grades 1, 2, 3, 4, 5, 6, 7, and 8). Ankara: MEB.

Monaghan, J. (2004). Teachers' activities in technology-based mathematics lessons. International Journal of Computers for Mathematical Learning, 9(3), 327-357.

Moore-Russo, D., Conner, A. M., \& Rugg, K. I. (2011). Can slope be negative in 3-space? Studying concept image of slope through collective definition construction. Educational Studies in Mathematics, 76(1), 3-21.

Patton, M. Q. (2002). Qualitative research and evaluation methods (3rd ed.). Thousand Oaks, CA: Sage.

Patton, M. Q. (2008). Utilization-focused evaluation (4th ed.). Thousand Oaks, CA: Sage.

Ruthven, K., Deaney, R., \& Hennessy, S. (2009). Using graphing software to teach about algebraic forms: A study of technology-supported practice in secondary-school mathematics. Educational Studies in Mathematics, 71(3), 279-297.

Samur-Turk, H. \& Akyuz, D. (2016). The effects of using dynamic geometry on eighth grade students' achievement and attitude towards triangles. The International Journal for Technology in Mathematics Education, 23(3), 95-102.

Simon, M. A., \& Blume, G. W. (1994). Mathematical modeling as a component of understanding ratio-as-measure: A study of prospective elementary teachers. Journal of Mathematical Behavior, 13(2), 183-197.

Smith, T. M., Seshaiyer, P., Peixoto, N., Suh, J. M., Bagshaw, G., \& Collins, L. K. (2013). Exploring slope with stairs \& steps. Mathematics Teaching in the Middle School, 18(6), 370-377.

Stump, S. (2001). High school precalculus students' understanding of slope as measure. School Science and Mathematics, 101(2), 81-89.

Tatar, E., \& Zengin, Y. (2016). Conceptual understanding of definite integral with Geogebra. Computers in the Schools, 33(2), 120-132.

Teuscher, D., \& Reys, R. (2010). Slope, rate of change, and steepness: Do students understand these concepts? Mathematics Teacher, 103, 519-524.

Thompson, P. W. (1994). The development of the concept of speed and its relationship to concepts of rate. In G. Harel \& J. Confrey (Eds.), The development of multiplicative reasoning in the learning of mathematics (pp. 179-234). Albany: State University of New York Press.

Yemen, S. (2009). İlköğretim 8. sinıf analitik geometri öğretiminde teknoloji destekli öğretimin öğrencilerin başarısına ve tutumuna etkisi. Unpublished Master's Thesis. Dokuz Eylül Üniversitesi, Eğitim Bilimleri Enstitüsü, İzmir.

Zahner, W. (2015). The rise and run of a computational understanding of slope in a conceptually focused bilingual algebra class. Educational Studies in Mathematics, 88(1), 19-41. 